\title{
Pengaruh Siklon Tropis Terhadap Tinggi Gelombang di Wilayah Selatan Jawa, Bali, dan Nusa Tenggara (Studi Kasus Siklon Tropis Claudia)
}

\section{Effect of Tropical Cyclones on High Waves in the Southern Regions of Java, Bali, and Nusa Tenggara (Case Study of Tropical Cyclones Claudia)}

\author{
Kholidatul Islamiyah $^{1 *}$, Komang Ngurah Suarbawa ${ }^{1}$, Kadek Sumaja ${ }^{2}$ \\ ${ }^{1}$ Jurus an Fisika, Fakultas Matematika dan Ilmu Pengetahuan Alam, Universitas Udayana, Kampus Bukit \\ Jimbaran, Badung, Bali, Indonesia 80361 \\ ${ }^{2}$ BMKG Stasiun Meteorologi Klas I Ngurah Rai, Gedung GOI Lt.2 Bandara Ngurah Rai, Badung, Bali, \\ Indonesia 80361 \\ Email:*kholidatul13@gmail.com; suarbawa@unud.ac.id; kadek.sumaja@gmail.com
}

\begin{abstract}
Abstrak - Secara geografis wilayah Indonesia berada pada daerah di bawahlintang $20^{\circ}$ (baik Utara maupun Selatan) memiliki kemungkinan yang kecil untuk tumbuhnya siklon tropis. Siklon tropis merupakan badai dengan kekuatan yang besar yang dapat mempengaruhi kondisi atmosfer dan perairan di wilayah Indonesia. Penelitian ini bertujuan untukmenganalisis karakteristik siklon tropis Claudia dan pengaruh siklon tersebut terhadap kondisi gelombang laut di wilayah Selatan Jawa, Bali dan Nusa Tenggara. Analisis yang dilakukan yaitu meliputi data satelit Himawari-8kanal IR digunakan untuk memantau intensitas kecepatan ang in dan tekanan udara di pusatsiklon dengan teknik Dvorak $T$ number. Data gelombang air laut untuk menggambarkan kondisi gelombang air laut. Hasil pengolahan data menunjukkan siklon tropis Claudia memliki masa hidup selama 16 hari dengan nilai maksimum $T$ number sebesar 4,5. Dampak siklon tropis Claudia pada kondisi gelombang air laut terjadi pada saat siklon tropis memasukitahap matang yaitu pada perairan Selatan Jawa Tengah hingga Nusa Tenggara Timur.
\end{abstract}

Kata kunci: Siklon tropis, Claudia, tinggi gelombang, teknik Dvorak, satelit Himawari-8.

\begin{abstract}
Geographically, Indonesia is located in areas belowlatitude $20^{\circ}$ (both north and south) and has little chance for tropical cyclones to grow. Tropical cyclones are storms with greatstrength that can affect the atmosphere and water conditions in the territory of Indonesia. This study aims to analyze the characteristics of tropical cyclone Claudia and the effect of the cyclone on sea wave conditions in the southern regions of Java, Baliand Nusa Tenggara. The analysis carried out includes data from the Himawari-8 satellite IR channel used to monitor the intensity of wind speed and air pressure at the center of the cyclone using the Dvorak T-number technique. Sea wave data to describe the condition of sea waves. The results ofdata processing showed that tropical cyclone Claudia had a life span of 16 days with a maximum T-number of 4.5. The impact of tropical cyclone Claudia on sea wave conditions occurs when the tropical cyclone enters the mature stage, namely in the southern waters of Central Java to East Nusa Tenggara.
\end{abstract}

Key words: Tropical Cyclone, Claudia, wave height, Dvorak technique, Himawari-8 satellite.

\section{Pendahuluan}

Sirkulasi lautan saling berhubungan dengan sirkulasi atmosfer dimana keduanya akan mengalami suatu interaksi fisik terutama di permukaan laut [1]. Interaksi laut dan atmosfer sangat sering terjadi di daerah tropis karena daerah ini sangat intensif dalam menerima radiasi matahari yang berakibat suhu permukaan laut di daerah tropis lebih tinggi di bandingkan dengan di daerah subtropis atau kutub. Oleh karena itu daerah tropis memiliki potensi terbentuknya pusat tekanan rendah yang dapat memicu terjadinya fenomena cuaca signifikan, salah satunya adalah siklon tropis [2]. Negara-negara yang berada di lintang tropis perlu memberikan perhatian lebih pada fenomena siklon tropis dan dampak yang ditimbulkan dari saat pembentukan hingga kepunahan. 
Secara geografis wilayah Indonesia berada pada daerah di bawah lintang $20^{\circ}$ (baik Utara maupun Selatan) memiliki kemungkinan yang kecil untuk tumbuhnya siklon tropis. Akan tetapi dampak yang ditimbulkan oleh siklon tropis terhadap wilayah Indonesia cukup nyata terlihat, terutama di wilayahwilayah yang dekat dengan daerah pertumbuhan siklon tropis [3]. Ketika ada indikasi pertumbuhan siklon tropis, kecenderungan cuaca di sekitarnya akan memburuk. Dampak siklon tropis dipengaruhi posisi dan intensitas siklon dan juga tergantung pada faktor sirkulasi udara di wilayah Indonesia [4]. Secara umum, terjadinya siklon tropis juga dapat memicu terjadinya gelombang tinggi di sekitar daerah pembentukannya.

Mengingat bahwa sangat signifikannya dampak bencana alam yang dapat diakibatkan oleh siklon tropis, maka perlu dilakukan penelitian terkait dampak kejadian siklon tropis sebagai salah satu bahan pertimbangan dalam membuat mekanisme sistem peringatan dini siklon tropis. Oleh karena itu, dalam penelitian ini akan dibahas dua parameter yang menjadi pokok perhatian dalam pembahasan terkait siklon tropis, yaitu pertama kondisi pertumbuhan aw an dan yang kedua kondisi perairan di wilayah Selatan Jawa, Bali dan Nusa Tenggara pada saat kejadian siklon tropis Claudia.

\section{Landasan Teori}

\subsection{Siklon tropis}

Siklon tropis didefinisikan sebagai sistem tekanan rendah non-frontal yang berskala sinoptik yang tumbuh di atas perairan hangat dengan wilayah perawanan konvektif dan kecepatan angin maksimum sedikitnya 34 knot pada lebih dari setengah wilayah yang melingkari pusatnya [5]. Ketika suhu permukaan laut tinggi, maka terbentuk pusat tekanan rendah yang dimulai dengan gangguan tropis lalu depresi tropis, badai tropis selanjutnya terjadi siklon tropis [1]. Siklon tropis terbentuk di atas lautan luas yang umumnya mempunyai suhu permukaan air laut hangat, lebih dari $26,5^{\circ} \mathrm{C}$. Angin kencang yang berputar di dekat pusatnya mempunyai kecepatan angin lebih dari $63 \mathrm{~km} / \mathrm{jam}$ [1]. Energi siklon tropis diperoleh dari lautan hangat. Oleh karena itu, siklon tropis akan melemah atau punah ketika bergerak dan memasuki wilayah perairan yang dingin atau memasuki daratan [5].

\subsection{Dvorak}

Dvorak merupakan sebuah metode yang biasa digunakan untuk memperkirakan intensitas siklon tropis hanya berdasarkan satelit [6]. Dvorak mengkaitkan perkembangan model pola perawanan dengan intensitas dari siklon tropis (laju angin maksimum dan tekanan minimum di atas permukaan laut) menggunakan Dvorak T-number. Metode Teknik Dvorak dibagi menjadi dua cara, yaitu analisis menggunakan kanal visible (VIS) dan analisis enhanced infrared images (EIR) menggunakan kanal infrared (IR) [7].

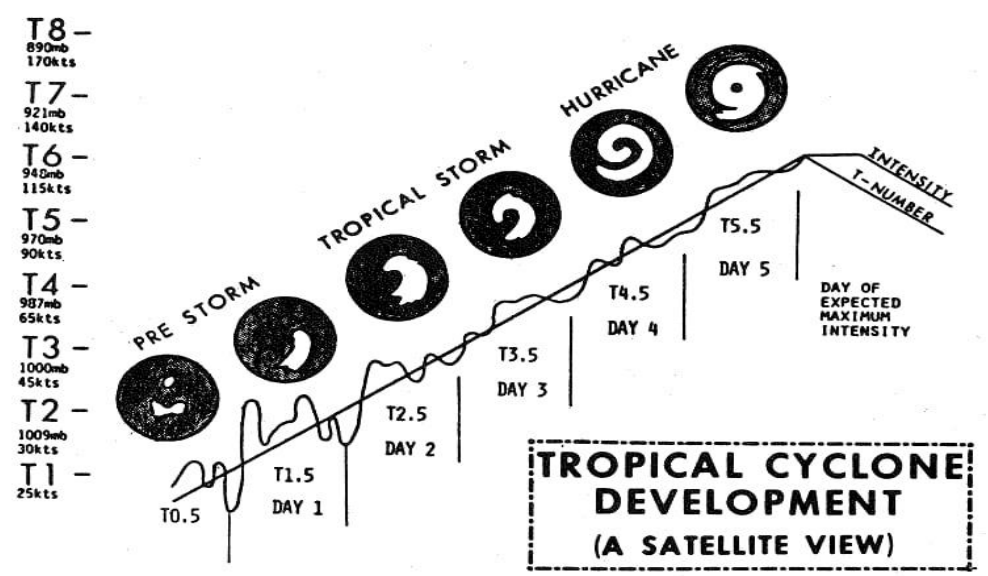

Gambar 1. Diagram Dvorak T-number [6].

Dalam perkiraan kekuatan Dvorak untuk siklon tropis, terdapat beberapa pola visual yang mungkin diambil oleh siklon yang menentukan batas atas dan bawah pada intensitasnya. Pola utama yang digunakan adalah pola pita melengkung melengkung (T1.0-T4.5), pola geser (T1.5-T3.5), pola mendung padat pusat (CDO) (T2.5-T5.0), penutup dingin pusat (CCC), pola pita mata (T4.0-T4.5), dan pola mata (T4.5-T8.0) yang ditunjukkan pada Gambar 1 [8]. 


\subsection{Gelombang laut}

Gelombang laut atau ombak yang terjadi di lautan dapat diklasifikasikan menjadi beberapa macam tergantung kepada pembangkitnya. Pembangkit gelombang laut dapat disebabkan oleh angin (gelombang angin), gaya tarik menarik matahari dan bulan terhadap massa air laut di bumi (gelombang pasang-surut), gempa (vulkanik atau tektonik) di dasar laut (gelombang tsunami), ataupun gelombang yang disebabkan oleh gerakan kapal [9]. Gelombang laut adalah pergerakan naik dan turunnya air dengan arah tegak lurus permukaan laut yang membentuk kurva atau grafik sinusoidal [10].

\section{Metode Penelitian}

Lokasi penelitian adalah Samudera Hindia bagian Selatan dengan Stasiun Meteorologi Klas I Ngurah Rai sebagai titik pengamatan. Wilayah yang dianalisis meliputi bagian Selatan Jawa, Bali, dan Nusa Tenggara. Data yang digunakan dalam penelitian ini meliputi data siklon tropis Claudia (05-15 Januari 2020) dari Bureau of Meteotology (BoM) Australia dan Badan Meteorologi Klimatologi dan Geofisika (BMKG), data rata-rata suhu permukaan laut (SPL) saat kejadian siklon tropis Claudia yang diperoleh dari NOAA (National Oceanic and Atmospheric Administrasion), data Satelit Himawari-8 Kanal IR yang diperoleh dari Sub-Bidang Pengolahan Citra BMKG dan data gelombang air laut diperoleh dari BMKG.

Pengolahan data dimulai dengan pengolahan data SPL harian yang berasal dari data reanalisis AVRR-NOAA dengan format .nc selama terjadinya siklon tropis Claudia. Selanjutnya data tersebut diolah menggunakan perangkat lunak SeaDAS versi 7.5.3 yang memberi hasil keluaran data berupa model windwave-05. Hasil pengolahan data SPL diperlukan sebagai salah satu penyebab terjadinya siklon tropis. Siklon tropis dapat berkembang ketika SPL hangat lebih dari $26^{\circ} \mathrm{C}$. Selanjutnya pengolahan data satelit Himawari-8 kanal IR yang diambil pada jam 00:00, 06:00, 12:00 dan 18:00 UTC selama terjadinya siklon tropis Claudia yaitu mulai tanggal 05 Januari 2020 hingga 15 Januari 2020 berupa data format .z kemudian diolah menggunkan aplikasi SATAID GMSLPD dari Japan Meteorological Agency (JMA) untuk melihat pertumbuhan awan pada pusat siklon tropis. Analisis meliputi kejadian sebelum, saat dan sesudah aw an terbentuk. Proses pengambilan data citra satelit menggunakan kanal infrared (IR) yang berbentuk citra. Hasil citra Himawari-8 dari SATAID kemudian dibandingkan dengan diagram Dvorak T-number, seperti ditunjukkan pada Gambar 1. Selanjutnya, pengolahan data kondisi gelombang laut selama terjadinya siklon tropis Claudia diolah dan dipetakan menggunakan aplikasi GrADS (Grid Analysis and Display System) dengan model Ina-wave. Hasil citra pengolahan data tersebut kemudian di identifikasi untuk melihat daerah raw an gelombang tinggi lebih dari $2 \mathrm{~m}$.

\section{Hasil Dan Pembahasan}

\subsection{Analisis suhu permukaan laut (SPL)}

Suhu permukaan laut merupakan salah satu faktor yang sangat penting dalam pembentukan siklon tropis. Hasil pengolahan data SPL selama terjadinya siklon tropis berupa citra diperlihatkan pada Gambar 2 .

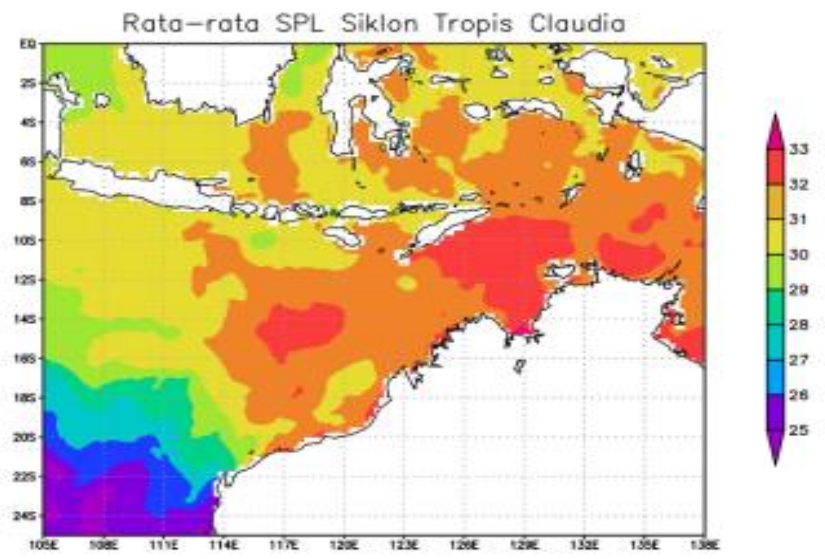

Gambar 2. Rata-rata SPL siklon tropis Claudia di bagian Selatan Jawa, Bali, dan Nusa Tenggara.

Berdasarkan Gambar 2 hasil rata-rata SPL selama terjadinya siklon tropis Claudia dimana daerah yang diamati yaitu pada lintasan dengan titik awal pada koordinat $135,4^{\circ} \mathrm{BT} ;-9,5^{\circ} \mathrm{LU}$ hingga berakhir pada koordinat $104,5^{\circ} \mathrm{BT} ;-21,0^{\circ} \mathrm{LU}$. Hal ini menunjukkan bahwa pada daerah lintasan siklon tropis kondisi SPL lebih hangat dari area sekitarnya. Suhu rata- rata mencapai $29^{\circ} \mathrm{C}-32^{\circ} \mathrm{C}$. Warna-warna pada 
hasil citra menunjukkan nilai SPL dengan skala $26^{\circ} \mathrm{C}$ hingga $33^{\circ} \mathrm{C}$. Energi panas yang ideal untuk membentuk siklon tropis dihasilkan pada perairan yang memiliki suhu permukaan laut diatas $26^{\circ} \mathrm{C}$ pada permukaan hingga kedalaman 50 meter [11].

4.2 Analisis pertumbuhan siklon tropis teknik Dvorak

Analisis pertumbuhan aw an dengan teknik Dvorak bertujuan untuk menentukan intensitas siklon tropis dengan memprakirakan nilai kecepatan angin dan tekanan udara dengan diagram Dvorak T-number. Dilakukan plotting data citra Himawari-8 kanal IR pada pusat siklon tropis agar intensitas siklon dapat dipantau dengan jelas. Hasil pengolahan data melalui pengamatan visual diperlihatkan pada Gambar 3.

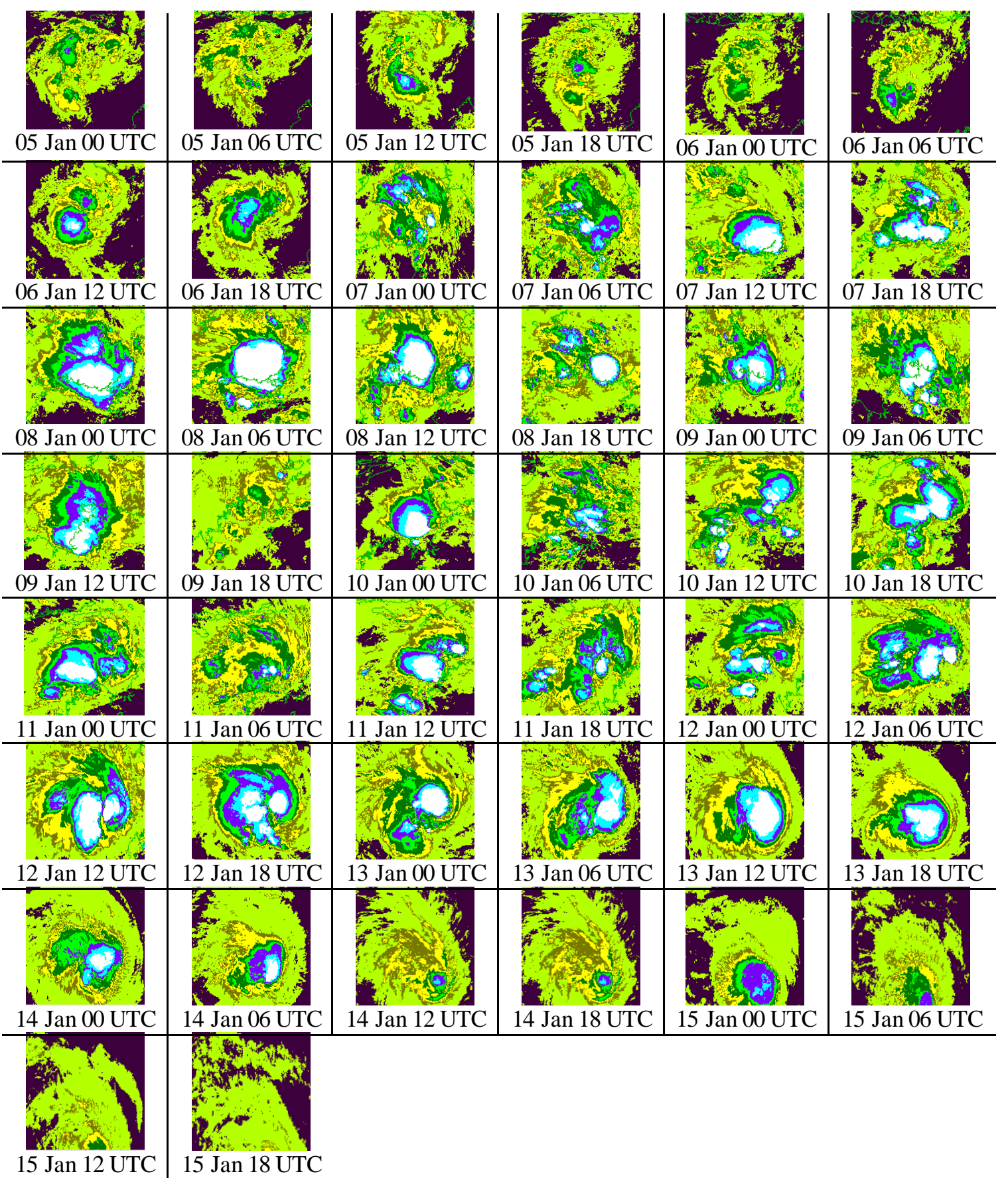

Gambar 3. Tahapan pembentukan siklon tropis Claudia di pusat siklon.

Berdasarkan Gambar 3 dapat diketahui bahwa pada tanggal 5 Januari 2020 pukul 06:00 UTC hingga 10 Januari 2020 pukul 18:00 UTC, terlihat pusat tekanan rendah yang ditandai dengan aktivitas konvektif, namun sistemnya masih tersebar dan belum terorganisir sebagai klaster awan MCS (mesoscale 
convective system), inilah tahap awal munculnya bibit siklon tropis yang disebut TD (tropical depression) dengan T-number berkisar T1,5-T2,0. Dari angka tersebut diperkirakan laju angin maksimum sebesar 15-30 knot dengan tekanan udara di atas 1000 hingga 1005 milibar. Pada tanggal 12 Januari 2020 pukul 18:00 UTC siklon tropis Claudia mulai masuk ke wilayah Laut Timor dan terus menguat dengan cepat menjadi siklon remaja ( $T$-number $=4,0)$ sampai pada tanggal 13 Januari 2020 pukul 12:00 UTC siklon tropis terus tumbuh hingga mulai menjadi dewasa dengan ditandai munculnya mata siklon dan mencapai puncaknya hingga pada tanggal 14 Januari 2020 pukul 06:00 UTC dengan kecepatan angin antara 65-80 knot dan tekanan sebesar 963-979 milibar di pusat siklon dengan nilai $T$-number $=4,5$ yang sama dengan TC Kategori-1. Siklon tropis Claudia terlihat mulai melemah pada 14 Januari 2020 pukul 12:00 UTC dan pada 15 Januari 2020 pukul 18:00 UTC terlihat mulai lenyap ditandai dengan $T$-number $=0,5$ yang mengindikasikan potensi konvektif yang sangat rendah.

\subsection{Analisis tinggi gelombang laut siklon tropis Claudia}

Anugrah et al (2010) mengungkapkan pada penelitiannya, saat memasuki musim hujan, siklon tropis tumbuh di sekitar perairan Laut Timor atau Teluk Carpentaria dan bergerak ke arah Barat atau Barat Daya. Sebagai contoh dari siklon yang terjadi pada musim hujan adalah siklon tropis Nelson (6-7 Februari 2007) dan siklon tropis George (3-9 Maret 2007) dimana siklon tropis tersebut mempengaruhi kondisi cuaca dan perairan di wilayah Selatan Nusa Tenggara, Bali, Jawa hingga Sumatera Selatan. Studi karakteristik siklon tropis (frekuensi dan intensitas) tersebut berdasarkan data selama 39 tahun (19692007) di Samudera Hindia bagian Selatan (termasuk siklon tropis yang dekat dengan perairan Selatan Jawa hingga NTT) [12]. Hal ini menunjukkan bahwa siklon tropis yang tumbuh di wilayah Selatan Indonesia berpeluang meningkatkan ketinggian gelombang air laut terutama saat lintasan siklon tropis dekat dengan wilayah Indonesia.

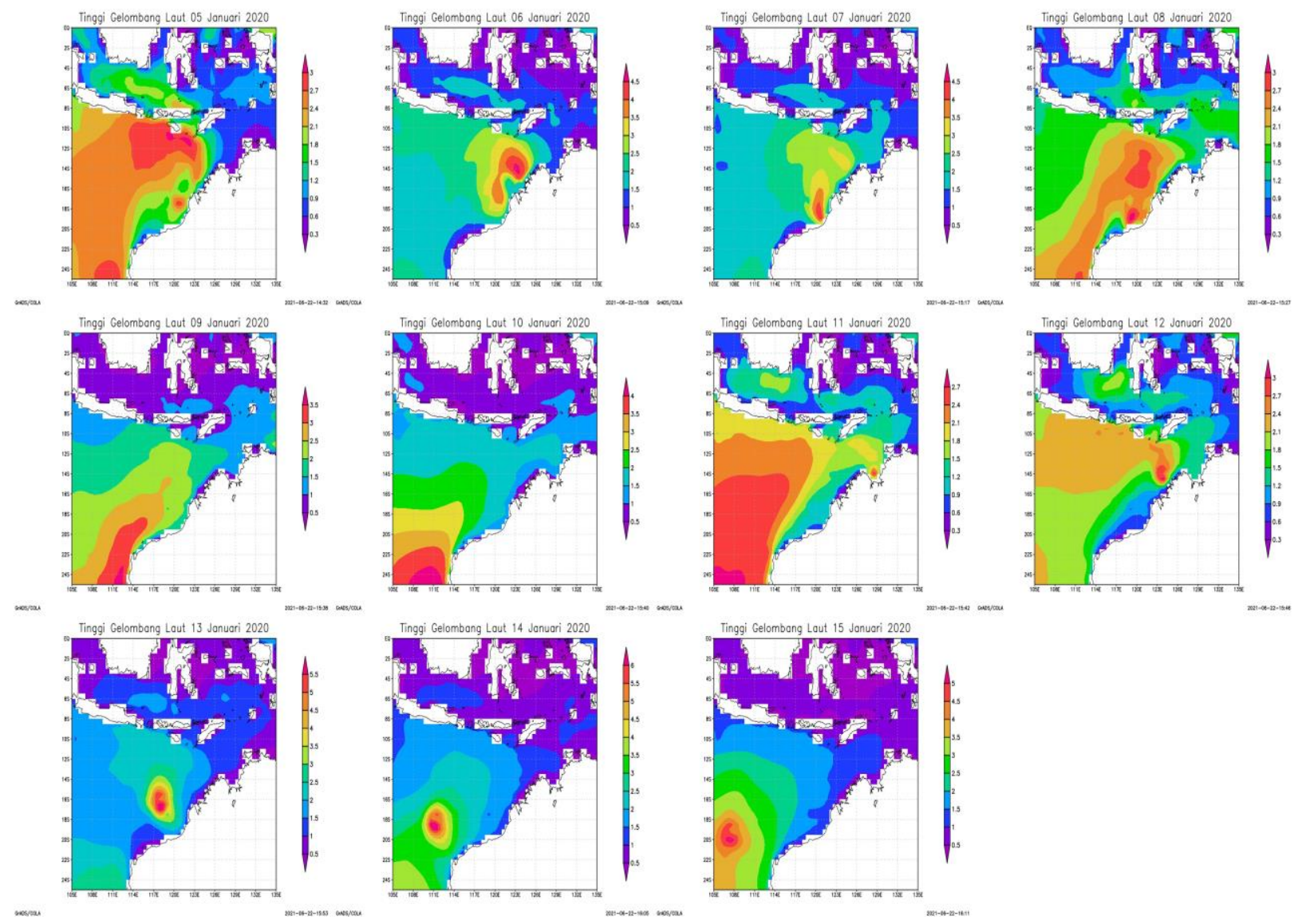

Gambar 4. Tinggi gelombang laut saat siklon tropis Claudia di wilayah Selatan Jawa, Bali dan Nusa Tenggara.

Berdasarkan hasil analisis tinggi gelombang laut yang ditunjukkan pada Gambar 4, pada saat siklon tropis Claudia masih berstatus depresi tropis pada tanggal 05 Januari 2020, kondisi tinggi gelombang pada daerah terbentuknya siklon umumnya masih rendah yakni berkisar 0,3-0,9 meter di wilayah Laut 
Arafura kecuali pada wilayah perairan Selatan Jawa, Bali dan Nusa Tenggara yang masih dipengaruhi oleh siklon tropis Blake berlangsung hingga tanggal 10 Januari 2020 di wilayah Australia Barat yaitu berkisar antara 1,5-3,0 meter. Pada tanggal 11 Januari 2020 saat kondisi siklon tropis Claudia sudah mulai mengalami tahap TS (Tropical Strom) ketinggian gelombang di wilayah lintasan siklon meningkat, ditandai dengan tinggi gelombang berkisar 1,5-1,8 meter meluas di wilayah bagian Selatan Pulau Jawa hingga Pulau Rote. Kemudian tanggal 12 Januari 2020 saat siklon mulai bergerak ke arah Barat Daya wilayah ketinggian gelombang sebesar 2,1 meter masih sangat luas yaitu pada wilayah Selatan Jawa Tengah hingga NTT dan ketinggian gelombang air laut di perairan Laut Timor mencapai 3 meter. Pada tanggal 13 Januari 2020 siklon tropis Claudia mulai menjauhi wilayah Indonesia dan terus bergerak ke arah Selatan dan siklon mencapai tahap puncaknya dimana ketinggian gelombang laut secara umum di wilayah Selatan Jawa, Bali hingga NTT berkisar 1,5-2 meter, dan pada titik pusat siklon ketinggian gelombang mencapai 5,5 meter yang diperlihatkan dari warna magenta di area pusatnya.

Kemudian pada tanggal 14 Januari 2020 ketinggian gelombang laut menurun yaitu berkisar 1,0-1,5 meter, dikarenakan semakin menjauhnya lintasan siklon tropis dari wilayah Indonesia. Pada tanggal 15 Januari 2020 tinggi gelombang laut terus menurun dimana ditandai dengan mulai punahnya siklon tropis Claudia. Dapat dilihat dari hasil yang aktifitas siklon tropis Claudia berdampak pada wilayah Selatan Jawa, Bali dan Nusa Tenggara tidak begitu signifikan hanya pada saat siklon mencapai puncaknya yaitu pada tanggal 12-13 Januari 2020 di wilayah Jawa Tengah hingga Nusa Tenggara ketinggian gelombang laut meningkat yaitu lebih dari dua meter. Siklon tropis yang tumbuh di wilayah lautan yang luas pada umumnya akan membuat kondisi gelombang di sekitarnya menjadi lebih tinggi dan berbahaya bagi para nelayan dan pengguna transportasi laut. Semakin skala siklon tropis meningkat, maka gelombang yang terjadi semakin tinggi [13].

\section{Kesimpulan}

Pertumbuhan siklon tropis Claudia mulai tahap awal hingga punah memiliki masa hidup selama 16 hari dan bergerak dari Utara menuju Barat Daya (Samudera Hindia). Berdasarkan citra aw an hasil pengolahan data Himaw ari-8 Kanal IR diketahui bahwa intensitas maksimum Dvorak T-number sebesar 4,5 masuk dalam Kategori-1 dengan prakiraan nilai tekanan udara antara 963-979 milibar dan kecepatan angin antara 65-80 knot di pusat siklon. Nilai suhu permukaan laut di lintasan siklon tropis berkisar $29^{\circ} \mathrm{C}-32^{\circ} \mathrm{C}$. Selain itu, dampak terjadinya gelombang tinggi di wilayah penelitian tidak terlalu signifikan pada fase pembentukan dan punah, namun hanya pada saat siklon mencapai tahap matang ketinggian gelombang laut meningkat lebih dari dua meter di wilayah perairan Selatan Jawa Tengah hingga Nusa Tenggara Timur.

\section{Ucapan Terima Kasih}

Terimakasih kepada Stasiun Meteorologi Klas I Ngurah Rai yang telah memberikan bantuan fasilitas dalam penelitian ini serta staf dosen bidang minat Fisika Kebumian, Prodi Fisika, Fakultas Matematika dan Ilmu Pengetahuan Alam, Universitas Udayana yang telah memberikan saran serta masukannya.

\section{Pustaka}

[1] P. Asrianti, A. Bey, Y. Ilhamsyah, et al., Kajian Beberapa Karakteristik Siklon Tropis (Kasus Topan Choi-wan dan Nida di Lautan Pasifik Utara Bagian Barat), DEPIK Jurnal Ilmu-Ilmu Perairan, dan Perikanan, vol. 2, no. 3, 2013, pp. 154-161.

[2] K. A. Emanuel, The maximum intensity of hurricanes. Journal of thr Atmospheric Sciences, vol. 45, Issue. 7, 1988, pp. 1143-1155.

[3] A. Zakir dan M. K. Khotimah, Badai dan Pengaruhnya Terhadap Cuaca Buruk di Indonesia, Jakarta, 2006.

[4] E. Perawiska, M. Muliadi, dkk., Analisis Unsur Cuaca Pada Saat Kejadian Siklon Tropis Haiyan Menggunakan Model Wrf (Weather Research and Forecasting), Prisma Fisika, vol. 6, no. 2, 2018, pp. 129-136.

[5] M. D. Syaifullah, Siklon tropis, karakteristik dan pengaruhnya di wilayah Indonesia pada tahun 2012. Jurnal Sains dan Teknologi Modifikasi Cuaca, vol. 16, no. 2, 2015, pp. 61-71.

[6] V. F. Dvorak, Tropical Cyclone Intensity Analysis using Satellite Data. NOAA Technical Report NESDIS 11, 1984, pp. 47. 
[7] Krismianto, Analisis Pertumbuhan, Pergerakan, dan Intensitas Siklon Tropis Marcia Berbasis Data Satelit MTSAT, Berita Inderaja, vol. 16, no. 1, 2015, pp. 37-45.

[8] M. A. Lander, A tropical cyclone with an anormous central cold cover, Monthly Weather Review, vol. 127, no. 1, 1999, pp. 132-136.

[9] Pratikno, W. A. dkk., Struktur Pelindung Pantai, Teknik Kelautan, Institut Teknologi Sepuluh Nopember, Surabaya, 2000.

[10] I. A. Rohman, Pemetaan Gelombang Laut dengan Metode Pemodelan Numerik dan Pemanfaatannya Untuk Mengidentifikasi Kerentanan Wilayah Pesisir terhadap Abrasi (Wilayah Studi: Kabupaten dan Kota Cirebon), Tugas Akhir, Institut Teknologi Bandung, Bandung, 2012.

[11] Gray, W. M., Global View of The Origin of the Tropical Disturbance and Stroms, Monthly Weather Review, vol. 96, no. 10, 1968, pp. 669-700.

[12] S. D. Anugrah, N. S. Ningsih, and H. Latief, The South Indian Ocean tropical Cyclones and Its Influences to The South Coast of Java, st Proceeding of the 1 Internasional Conference on Sustainable Built Environment (ICSBE), Yogyakarta, Indonesia, 2010.

[13] R. Prasetya, As'ari, dan W. Dayantolis, Analisis Dampak Siklon Tropis Nangka, Parma dan Nida pada Distribusi Curah Hujan di Sulawesi Utara, Jurnal Fisika dan Aplikasinya FMIPA ITS, vol. 10, no. 1, 2014, pp. 1-9. 